\title{
Role of primary to re-equilibrated fluids during P-T evolution from Nagthat Siliciclastic of Lesser Himalaya, India
}

\author{
Priti Verma* and Rajesh Sharma \\ Wadia Institute of Himalayan Geology, Dehradun, INDIA \\ *To whom correspondence should be addressed.E-mail:preity_ver@yahoo.com
}

Tiny droplets, the fluid inclusions (FI) or the paleofluids that represents the mother fluid system existed during the growth of the host crystal with subsequent geological events. Fluid inclusion studies have been carried out to define PVTX properties of the basinal fluids and their participation in the evolution of the rocks. $\mathrm{H}_{2} \mathrm{O}-\mathrm{NaCl}, \mathrm{H}_{2} \mathrm{O}-\mathrm{CO}_{2}-\mathrm{NaCl}, \mathrm{CO}_{2}$ type fluid phases are noticed in the rocks of Lesser Himalayan sedimentary terrane. The distribution pattern of these inclusions varies as primary, secondary and re-equilibrated type of fluid phases that reveals the depositional history and post-deformational events. Primary FI trapped during the crystallization of the host mineral are the representative of early fluid trapped before deformation and recrystallisation. The post-deformational event directed variable $\mathrm{P}-\mathrm{T}$ conditions in the system. The internal pressure inside the inclusions exceeds the confining pressure which may result into partial or complete change in the shape of the cavity with disturbing the original fluid content. The development of the requilibration textures such as $\mathrm{C}$ - shape, annular ring, decreptation clusters, stretching signifies high internal pressure $>$ confining pressure. Sudden fall in pressure at constant temperature generates high internal overpressure inside the inclusion cavity that follows the isothermal decompression path.

Proterozoic Nagthat formation of Lesser Himalaya is exceptionally arenitic in nature showing the presence of two different generatons of quartz i.e. primary detrital and recrystallised ones. The majority of homogeneous $\mathrm{H}_{2} \mathrm{O}-\mathrm{NaCl}$ are present in both type of crystallization but $\mathrm{H}_{2} \mathrm{O}-\mathrm{CO}_{2}-\mathrm{NaCl}$ heterogeneous FI are exclusively present in detrital quartz grains. Primary biphase aqueous inclusions cover 70 to 90 volume percent of liquid with a contemporary vapor phase and are mostly isolated in appearance but sometimes random pattern of distribution are also noticed in detrital quartz grains. Tiny monophase aqueous inclusions are frequently noticed in recyrtallised type of quartz grains. The first melting temperature of primary saline aqueous inclusions indicate the presence of $\mathrm{H}_{2} \mathrm{O}-\mathrm{NaCl}$ fluid with homogenization temperature of 121 to $232^{\circ} \mathrm{C}$ and salinity in the range of 3.8 to $11.1 \mathrm{wt} \% \mathrm{NaCl}$.

Fluid immiscibility representing the heterogeneous trapping of $\mathrm{H}_{2} \mathrm{O}-\mathrm{NaCl}, \mathrm{H}_{2} \mathrm{O}-\mathrm{CO}_{2}-\mathrm{NaCl}, \mathrm{CO}_{2}$ aqueous and carbonic phase is noticed in subrounded detrital quartz. The eutectic temperature of these inclusions at $-56.6^{\circ} \mathrm{C}$ confirms the presence of pure $\mathrm{CO}_{2}$ in inclusions and their complete homogenization ranges between -1 to $-2{ }^{\circ} \mathrm{C}$ denoting the density of $0.9 \mathrm{gm} / \mathrm{cm}^{3}$. Such type of primary $\mathrm{CO}_{2}$ entrapment is predicted to have been originated from protolith of the sandstone during quartz crystallization phase.

The suturing of crystal or mineral due to post-depositional deformation events consequence the growth of fluid inclusions in linear fashion, which crosscuts the grain boundary. These linear arrays of different generations, sometimes crosscutting each other, represent two stages of deformation. Two different sets of microfractures are filled with monophase and biphase aqueous inclusion of less than 5 micron in size. Each successive trapping of inclusion trail can establish a good chronological record. The

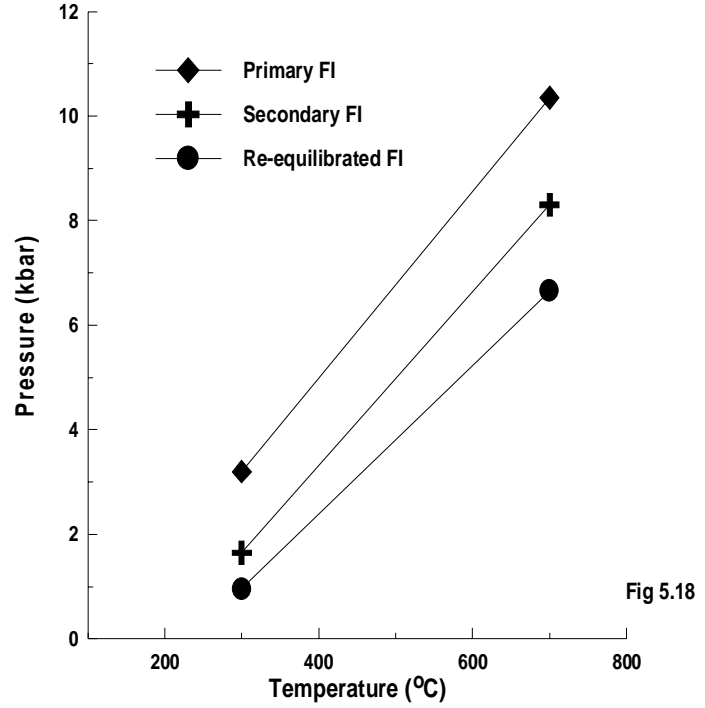

FIGURE 1. Isochors for Nagthat formation of Lesser Himalaya, India

most recent trail developed in the process is considered to be the youngest which can reveal the youngest activity prevailed after deposition. The homogenization of these secondary inclusions in quartz varies in the range of 198 to $232^{\circ} \mathrm{C}$ with salinity between 2 to 14.5 wt\% $\mathrm{NaCl}$.

The re-qulibration of primary fluid due to high internal pressure $>$ confining pressure develops several features like stretching of the inclusion cavity, their migration, satellite inclusion cavities etc in the quartz grains showing varied degree of recrystallisation. The homogenization temperature of these inclusions ranges between 187.5 to $235^{\circ} \mathrm{C}$ and salinity between 2 to 8.4 wt\% $\mathrm{NaCl}$.

The mineral relationship and fluid role support two stages of diagenesis i.e. locomorphic stage showing $>80 \%$ quartz and low concentration of altered minerals such as sericite, chlorite and other clay minerals and phyllomorphic with the development of physillites and pressure shadows, suggested two periodic episodes of diagenesis below $250^{\circ} \mathrm{C}$.

The P-T estimation of these rocks can be done by measuring total homogenization temperature and estimated pressure; the isochore (iso- Th line) of different fluid phase's i.e. primary, secondary and re-equilibrated inclusions can reveal the evolution of the rock in the sedimentary basin. The P-T interpretation for Nagthat formation siliciclastic is plotted in Figure 1, which shows the iso-Th lines for primary, secondary and re-equilibrated fluids in succession and reveals:

$\sim$ Transportation of the sediments from the source and its deposition in the basin supported by carbonic FI

$\sim$ External deformation of rock and suturing of mineral and growth of secondary fluid inclusions

$\sim$ Re-equilibration of primary fluid during intense deformation. 